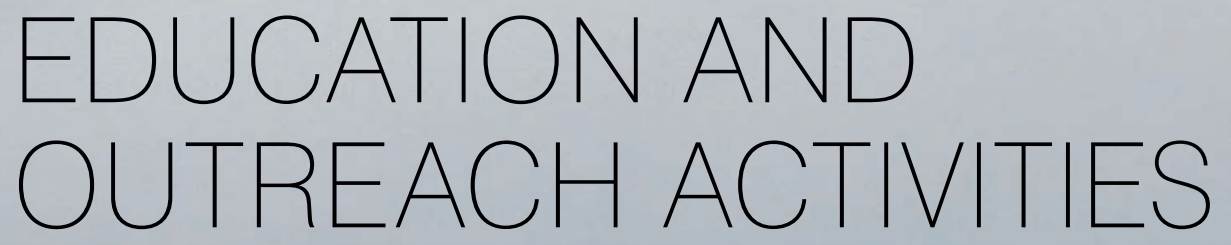

\title{
RESEARCH ACTIVITIES IN ANTARCTICA AS PART OF THE CONTINUING EDUCATION PROJECT "ZOOLOGY IN FOCUS" AT THE STATE UNIVERSITY OF PONTA GROSSA (UEPG)
}

Susete Wambier Christo ${ }^{1}$, Denilton Vidolin ${ }^{1}$, Augusto Luiz Ferreira Júnior ${ }^{2}$, Theresinha Monteiro Absher ${ }^{2}$

1Departamento de Biologia Geral - DEBIO, Universidade Estadual de Ponta Grossa - UEPG.

Rua Barão de Monte Alegre,361,CEP 81540-200 Curitiba - PR, Brazil.

${ }^{2}$ Centro de Estudos do Mar - Universidade Federal do Paraná

Av. Beira-Mar, s/n. Caixa Postal: 50.002. CEP 83255-971. Pontal do Paraná-PR, Brazil.

*email: swchristo@hotmail.com; wambchristo@yahoo.com.br

https://doi.org/10.4322/apa.2016.019

The habit of just using the classroom as a teaching environment restrains learning conditions. Therefore, new resources for learning are fundamental to quality education. Advancements related to a formative and innovative school implicates the use of appropriate didactic resources and an emphasis in interaction between students and teachers. In this context, the Antarctic continent is still little explored with regard to the teaching of Sciences and barely mentioned

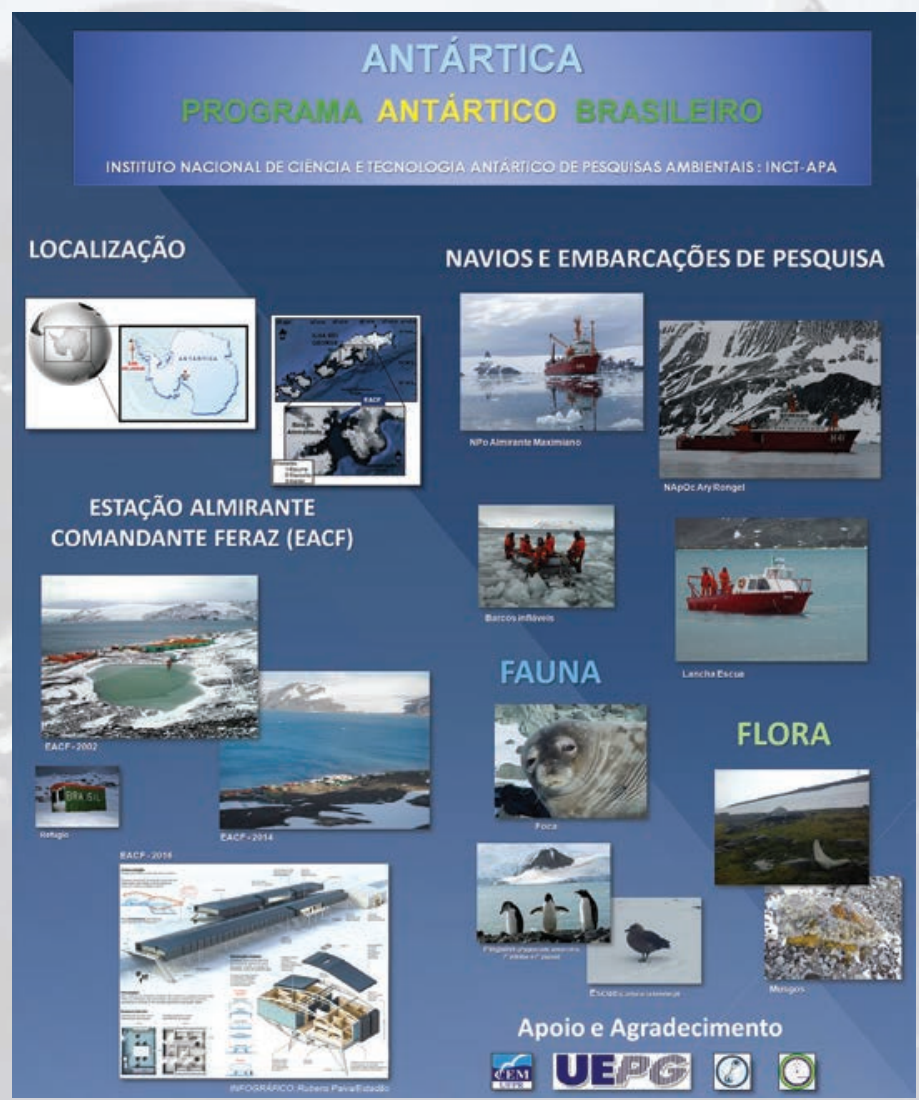

Figure 1. Panels related to the diversity and procedures used for sampling during Brazilian expeditions to the Antarctic. 
in, or even excluded of, text books for elementary and secondary school. It is known that the use of demonstrative materials from didactic collections and museums can make this learning more significant and help understanding of the contents of sciences. Based on this problem, this work aimed to inform in a didactic manner elementary, high school and university students, as well as the local community, of research activities related to Instituto Nacional de Ciência e Tecnologia Antártico de Pesquisas Ambientais (INCT-APA) [National Institute of Science and Technology on Antarctic Environmental Research].

The didactic activities took place at the Zoology Laboratory/Department of General Biology in the State University of Ponta Grossa - Paraná, Brazil. In 2014, a didactic exhibition on the theme "Antarctica" was held, where equipment and samples of organisms collected during expeditions to the Antarctic were exhibited, in addition to illustrative panels related to the procedures and equipment used for sampling (Figure 1).

The exhibition is part of the continuing education project "Zoology in Focus" and is annually held at UEPG with the aid of undergraduate students of the Biological Sciences course (Figure 2). The activities were accomplished in the morning, afternoon and night periods for students attending different periods and courses. At the same time, a collection of results of Antarctic research, obtained by the INCT-APA, is being worked out.

Lectures on the impact of anthropic activity on the Antarctic environment were held for the students and teachers of the Ponta Grossa State University post-graduate

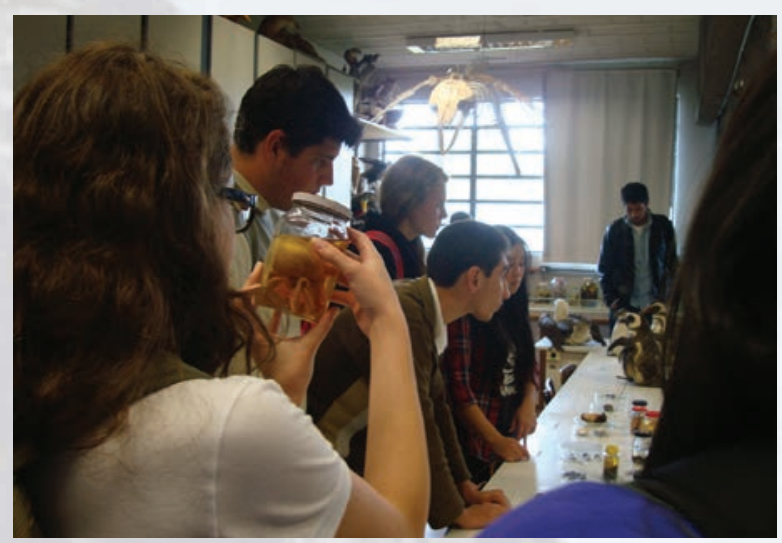

Figure 2. Curiosity and satisfaction of the local community and students during the exhibition on the diversity of the Antarctic. program in Biological Sciences, in concentration area Evolutionary Biology.

The teachers were questioned about the activities developed in the Antarctic projects, if these were expected in relation to the school activities. The participants were questioned as to their degree of satisfaction and knowledge acquisition from the exhibition.

The results obtained with the exhibition demonstrated the curiosity and satisfaction on the theme proposed. As a result of the exhibition, a note was published on the University's website and an interview was broadcast by the local Educational TV (Figure 3). More than 100 visits to the exhibition by undergraduate students of different courses of UEPG, employees, and the local community were registered (Figure 2 and 3 ).

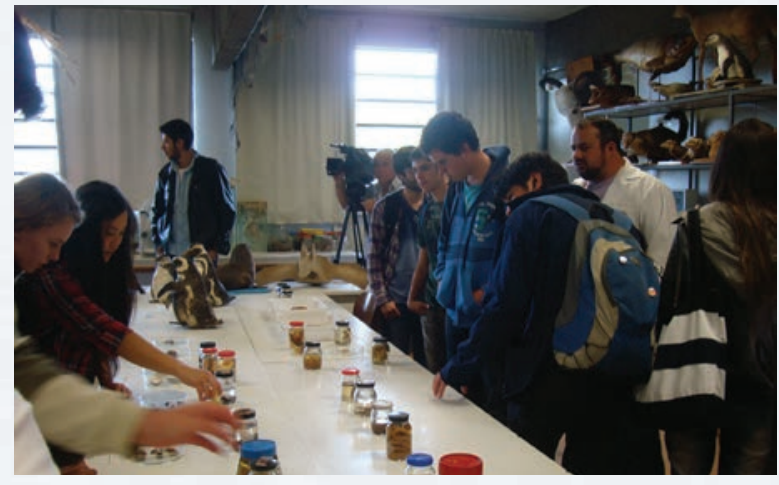

Figure 3. Interaction between students and teachers during the exhibition Antarctica, linked to the continuing education project "Zoology in Focus".

\section{Acknowledgements}

This work integrates Instituto Nacional de Ciência e Tecnologia Antártico de Pesquisas Ambientais (INCTAPA) [National Institute of Science and Technology on Antarctic Environmental Research] receiving scientific and financial support from Conselho Nacional de Desenvolvimento Científico e Tecnológico [National Council for Scientific Research and Development] (CNPq, process $n^{\circ}$ 574018/2008-5) and Fundação de Amparo à Pesquisa do Estado do Rio de Janeiro [Carlos Chagas Research Support Foundation in Rio de Janeiro] (FAPERJ, $n^{\circ}$ E-16/170.023/2008). The authors also acknowledge the support of Brazilian Ministries of Science, Technology and Innovation (MCTI), Environment (MMA), and the InterMinistry Commission for Sea Resources (CIRM). 